\title{
Aplikasi Surat Pertanggung Jawaban Kegiatan Dana Bantuan Operasional Kesehatan Pada Puskesmas Bati - Bati Berbasis Web
}

\author{
Agustian Noor ${ }^{1}$, Arif Supriyanto ${ }^{2}$ \\ ${ }^{1}$ Teknik Informatika, Politeknik Negeri Tanah Laut \\ 2IImu Komputer, Politeknik Negeri Tanah Laut \\ agustiannoor@politala.ac.id ${ }^{1}$
}

\begin{abstract}
Abstrak
Pada badan kesatuan bangsa dan politik yang ada di kabupaten Tanah Laut sebenarnya sudah ada sistem yang dibuat untuk menangani masalah kepegawaian yang ada dilingkungannya. Namun demikian, hal tersebut masih terdapat banyak kekurangan pada sistemnya. Hal pertama terlihat pada status pensiun karyawan, pada sistem informasi ini belum ada fitur yang dapat mengetahui kapan pegawai tersebut pensiun, hal ini jelas sangat merugikan pihak badan kesatuan bangsa dan politik kabupaten tanah laut, sebab pegawai yang sudah pesiun bisa saja masih terdaftar pada sistem. Selama ini admin tidak dapat mengetahui kapan pegawai tersebut akan pesiun, karena tidak adanya fitur yang dibuat untuk mengetahui informasi tersebut. Berdasarkan penjabaran dari penjelasan tersebut, maka diperlukan sebuah pengembangan sebuah sistem informasi kepegawaian yang dapat mengelola data pensiun dan mengelola data golongan secara berkala. Dalam mengembangkan aplikasi tersebut penulis menggunakan metode waterfall dengan menggunakan bahasa pemrograman PHP (Framework Codeilgniter), HTML, CSS, JavaScript, dan dirancang menggunakan Entity Relationship Diagram , Data Flow Diagram dan Flowchart. Aplikasi ini diharpakan dapat membantu dalam melihat data pegawai yang pensiun..
\end{abstract}

Kata Kunci : Sistem Informasi, Pegawai, Pensiun, dan Pengembangan.

\begin{abstract}
In the national and political unitary body in Tanah Laut district, there is actually a system created to deal with staffing problems in the environment. However, there are still many shortcomings in the system. The first thing is seen in the retirement status of employees, in this information system there is no feature that can know when the employee retires, this is clearly very detrimental to the national and political unitary body of Tanah Laut Regency, because retired employees may still be registered in the system So far, the admin cannot know when the employee will retire, because there is no feature made to find out this information. Based on the description of the explanation, it is necessary to develop a personnel information system that can manage pension data and manage class data on a regular basis. . In developing the application, the author uses the waterfall method using the PHP programming language (Framework Codeilgniter), HTML, CSS, JavaScript, and is designed using Entity Relationship Diagrams, Data Flow Diagrams and Flowcharts. This application is expected to be able to assist in viewing the data of retired employees.
\end{abstract}

Keywords: Information Systems, Employees, Retirement, and Development.

\section{Pendahuluan}

Pusat Kesehatan masyarakat atau puskesmas

adalah pasilitas layanan masyarakat yang bertujuan untuk mencapai derajat Kesehatan masyarakat yang setinggi-tingginya. Pada setiap daerah miliki pusat Kesehatan masyarakat, dan 
salah satunya adalah kecamatan bati-bati. puskesmas bati bati terletak di Jalan A. Yani, Ds. Padang, Kecamatan Bati-bati, Kabupaten Tanah Laut Pada sebuah instansi terutama puskesmas bati-bati memiliki karyawan yang miliki tugas nya masing-masing yang harus dilaksanakan, dimana hampir semua kegiatan membutuhkan biaya operasional.

Pemerintah sendiri sudah memberikan solusi melalui program BOK(Bantuan Operasional Kesehatan) yang merupakan subsidi pemerintah dalam bidang Kesehatan. Bantuan ini ditujukan untuk membiayai pelayanan Kesehatan yang selama ini dirasa kurang memadai. BOK diperuntukkan untuk meningkatkan pusat pelayanan Kesehatan masyarakat (puskesmas) agar kesenjangan pelayanan Kesehatan antara puskesmas dan rumah sakit terutama pelayaan preventif Kesehatan semakin tipis. Pemanfaatan dana BOK di puskesmas digunakan untuk operasional pelayanan Kesehatan dan manajeman puskesmas antara lain, transportasi, kebutuhan kantor sperti ATK, kegiatan luar sepeti penyuluhan kepada masyarakat, biaya administrasi perbankan, pengiriman surat dan lain nya.

Akan tetapi sulitnya memanajeman data perjalanan dinas dan kebutuhan operasional lainya yang membuat rancunya oleh karena itu dilakukan lah pengembangan sistem Aplikasi Surat Tugas Perbelanjaan dinas Pada
Puskesmas bati-bati utuk memantau seluruh kegiatan pegawai dan kebutuhan puskesmas bati-bati yang membutuh kan biaya operasional agar termonitor dengan baik.

\section{Tinjauan Pustaka}

\subsection{Penelitian Terkait}

Kerangka penelitian dari Pengembangan Sistem Aplikasi Surat Tugas Perjalanan Dinas Pada Puskesmas Bati-Bati Berbasis Web yang dirancang oleh penulis adalah sebagai berikut :

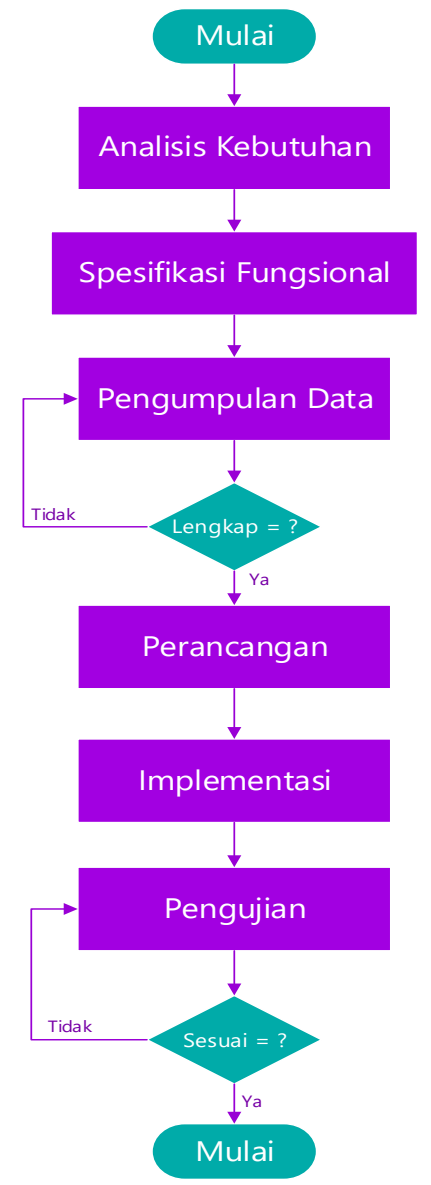

Gambar 1. Kerangka Penelitian 
Tahap pertama pada penelitian kali ini adalah analisis kebutuhan. Pada tahap ini penulis melakukan analisis mengenai apa saja yang dibutuhkan untuk penelitian ini. Aplikasi ini dibangun untuk mengembangkan Aplikasi surat tugas perjalanan Dinas Pada Puskesmas BatiBati Berbasis Web yang telah ada sebelumnya. Disini penulis diharapkan mencari kelemahan pada sistem informasi kepegawaian yang sudah ada badan kesatuan bangsa dan politik kabupaten tanah laut.

Berdasarkan analisa yang telah dilakukan oleh penulis, maka kebutuhan yang diperlukan untuk melakukan pengembangan Aplikasi Surat Tugas Perjalanan Dinas ini adalah data data-data terkait penyempurnaan dari aplikasi surat tugas.

\section{Metode Penelitian}

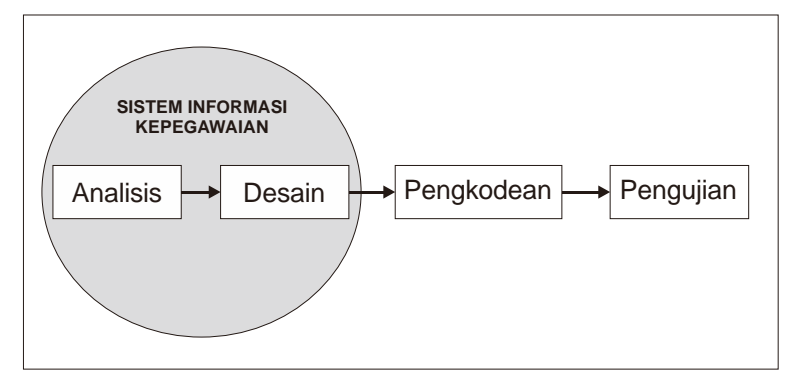

Gambar 2. Metode Pengmbangan Sistem

Berikut tahapan-tahapan metode waterfall yang penulis implementasikan pada perencanaan pembuatan sistem ini:
1. Analysis (analisis)

Tahap pertama adalah analisis. Penulis melakukan proses pengumpulan kebutuhan perangkat lunak. Kemudian penulis menganalisa data-data apa saja yang akan digunakan, secara garis besar, alur sistem yang dibangun dimulai dari seorang Pegawai yang melakukan pembuatan dan pengelolaan data SPT dan SPPD. Proses pembuatan masih menggunakan Microsoft Office dan pengelolaan dilakukan secara manual. Hingga pembuatan laporan harus dilakukan secara manual juga. Pegawai membuat SPT dan SPPD dengan menggunakan Microsoft Office kemudian dicetak[1]

\section{Design (Desain)}

Pada tahapan ini dilakukan proses perancangan pada bagian desain sistem yang akan dibangun, baik struktur data, arsitektur perangkat dan antarmuka program. Desain perangkat lunak adalah proses multi langkah yang fokus pada desain pembuatan program perangkat lunak termasuk struktur data, arsitektur perangkat lunak, representasi antarmuka, dan prosedur pengkodean. Pada tahap ini, penulis menggunakan ERD, DFD, Flowchart, dan rancangan antar muka menggunakan aplikasi Balsamic Mockup untuk membuat perancangan dari sistem, yang nantinya akan digunakan untuk mentranslasi kebutuhan ke representasi desain agar dapat diimplementasikan menjadi program pada tahapan selanjutnya[2][3]. 


\section{Coding (Pengkodean)}

Setelah dilakukan tahapan desain, maka hasil yang didapat di terapkan pada proses pembuatan Coding (pengkodean) program menggunakan bahasa pemrograman yang telah ditentukan. Desain harus ditranslasikan ke dalam program perangkat lunak. Hasil dari tahap ini adalah program komputer sesuai dengan desain yang dibuat pada tahapan desain, untuk pembangunan sistem penulis menggunakan bahasa pemrograman PHP (Hypertext Prepocessor) menggunakan Framework Codeigniter, HTML (Hypertext Markup Language) digunakan untuk mendefinisikan struktur halaman web, CSS (Cascading Style Sheet) sebagai bahasa yang digunakan untuk mengatur tampilan (gaya) elemen-elemen HTML, MySQL (My Structured Query Language) digunakan sebagai database didalam memuat data dan Javascript digunakan untuk membuat halaman web yang lebih interaktif[4]. Sementara itu, Visul Studio Code digunakan untuk text editor dalam pengkodean (codingan).

\section{Testing (Pengujian)}

Tahap testing atau tahapan pengujian adalah proses menguji hasil sistem yang telah dibangun, baik dari segi antarmuka (interface), fungsi dan fitur program. Pengujian fokus dari segi fungsional dan memastikan bahwa semua bagian sudah diuji. Hal ini dilakukan untuk meminimalisir kesalahan dan memastikan keluaran yang dihasilkan sesuai dengan yang diinginkan, pada tahap ini penulis menggunakan sistem pengujian black box.

\section{Hasil dan Pembahasan}

1. Analisis yang berjalan

Analisis sistem dilakukan untuk mengidentifikasi sebuah sistem yang berjalan guna mencari kelebihan dan kekuarangan dari sebuah sistem yang ada[4]. Analisa sistem yang dilakukan ada dua jenis yaitu sistem yang sedang berjalan dan sistem yang akan diusulkan. Berikut adalah adalah penjabaran :

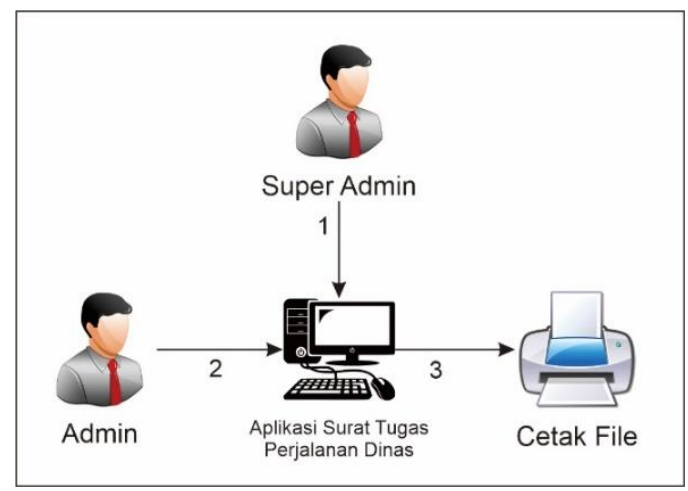

Gambar 3. Sistem yang diusulkan

\section{Implementasi Sistem}

Berikut ini adalah implementasi dari halaman Login pada Pengembangan Aplikasi Surat Tugas Perjalanan Dinas Pada Puskesmas Bati-Bati Berbasis Web yang telah dirancang. 


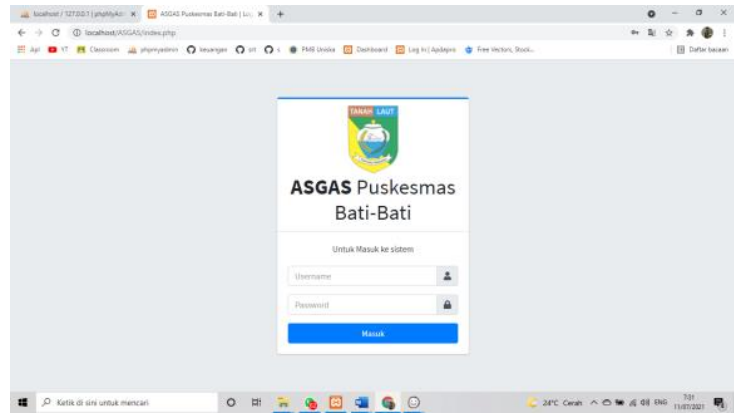

Gambar 4. Halaman Login

Implementasi Halaman Login mendeskripsikan tentang rancangan dari halaman login. Penulis merancang halaman login untuk masuk kedalam sebuah aplikasi. Pada bagian inputan data, penulis menggunakan dua buah inputan yang berbeda, pada inputan pertama user harus memasukkan username yang sudah dibuat oleh penulis. Setelah menginputkan username, user harus menginputkan password yang telah dibuat. Inputan password akan dibuat hidden atau disembunyikan agar orang-orang tidak dapat mengetahui kode password yang dimasukkan oleh user pada saat akan melakukan proses login. Jika user ingin melihat password, maka user bisa menekan icon lihat password yang ada pada aplikasi. Setelah username dan password dimasukkan maka user mengklik button login untuk masuk kehalaman dashboard.

Berikut ini adalah implementasi dari halaman Tampil Surat Tugas pada level Super Admin pada Pengembangan Aplikasi Surat Tugas Perjalanan Dinas Pada Puskesmas Bati-Bati Berbasis Web yang telah dirancang.

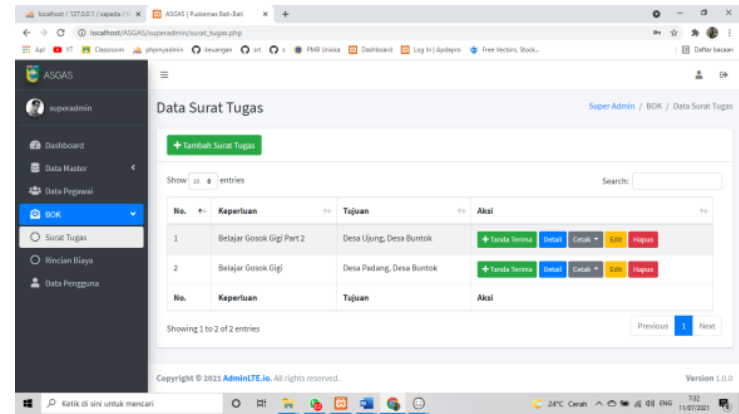

Gambar 5. Halaman Surat Tugas

Implementasi halaman tampil surat tugas dari level super admin adalah rancangan yang dibuat penulis untuk menampilkan data-data surat tugas mulai dari data keperluan surat tugas, tujuan surat tugas, dan aksi yang dapat diberikan oleh pengguna aplikasi. Aksi dalam surat tugas ini terbagi menjadi button cetak, button detail, button tambah, button edit dan button hapus. Button cetak dirancang untuk mencetak data surat tugas. Button detail dirancang untuk menampilkan detail data dari surat tugas. Button tambah dibuat untuk menambah data surat tugas. Button edit dibuat untuk mengubah data surat tugas. Button hapus dibuat untuk menghilangkan data surat tugas. Selain itu ada juga fitur search untuk mencari data surat tugas yang diingikan oleh pengguna aplikasi.

Berikut ini adalah implementasi dari halaman Tampil Data detail surat tugas pada level super admin pada Pengembangan Aplikasi Surat Tugas Perjalanan Dinas Pada Puskesmas Bati-Bati Berbasis Web yang telah dirancang. 


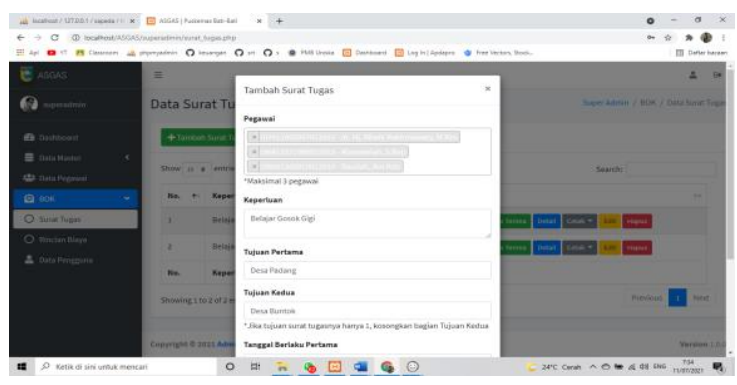

Gambar 6. Halaman Super Admin

Berikut ini adalah implementasi dari halaman hapus data surat tugas pada level super admin pada Pengembangan Aplikasi Surat Tugas Perjalanan Dinas Pada Puskesmas Bati-Bati Berbasis Web yang telah dirancang.

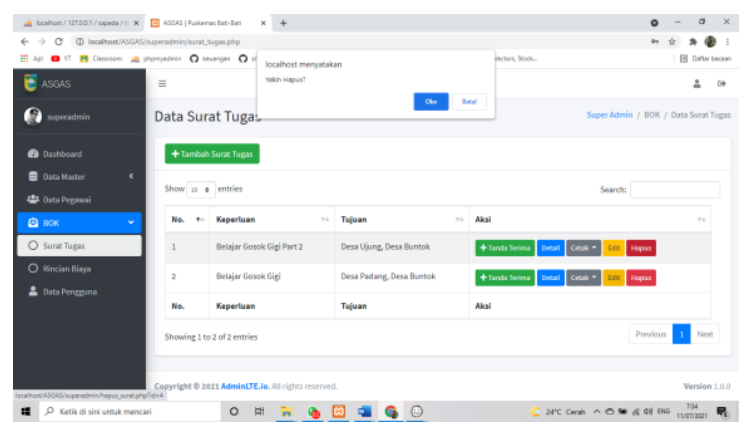

Gambar 7. Halaman Hapus Surat Tugas

Implementasi halaman hapus surat tugas pada level super admin ini berguna untuk menghapus data surat tugas pada level admin. Data surat tugas yang dihapus yaitu meliputi data nip dan nama pegawai yang dipilih, ubah data keperluan didalam surat tugas, ubah data tujuan pertama, ubah data tujuan kedua, ubah data tanggal berlaku pertama, ubah data tanggal berlaku kedua dan jika data sudah benar maka kita bisa menyimpan hasil hapus data yang telah dihapus oleh user dengan melakukan klik pada button oke akan membuat data surat tugas menjadi hilang atau terhapus. Jika perubahan data dirasa tidak benar atau data tidak jadi berubah maka user bisa melakukan klik pada button tutup untuk menutup modal pada Aplikasi Surat Tugas Perjalanan Dinas Pada Puskesmas Bati-Bati Berbasis Web yang sudah dikembangkan.

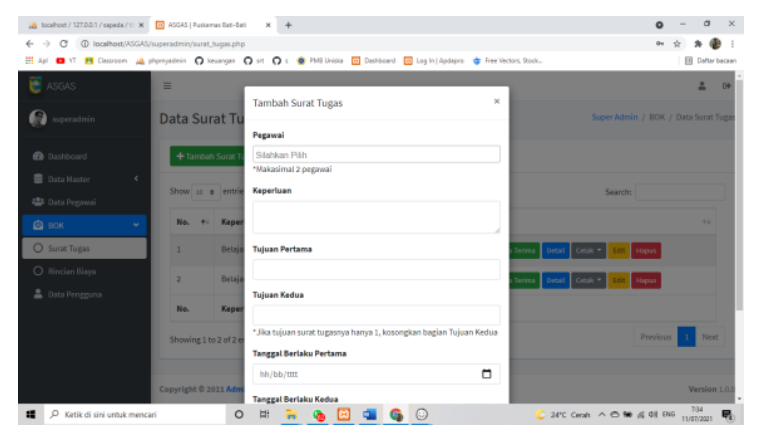

Gambar 8. Halaman Tambah Surat Tugas

Implementasi halaman tambah surat tugas pada level super admin ini berguna untuk menambahkan data surat tugas pada level admin. Data surat tugas yang ditambahkan kedalam aplikasi yaitu meliputi data nip dan nama pegawai yang dipilih, tambah data keperluan didalam surat tugas, tambah data tujuan pertama, ubah data tujuan kedua, tambah data tanggal berlaku pertama, tambah data tanggal berlaku kedua dan jika data sudah benar maka kita bisa menyimpan hasil penambahan data yang telah ditambahkan oleh user dengan melakukan klik pada button simpan. Jika penambahan data dirasa tidak benar 
DOI : 10.29408/jit.v5i1.4685 Link : https://dx.doi.org/10.29408//jit.v5i1.4685

atau data tidak jadi berubah maka user bisa melakukan klik pada button tutup untuk menutup modal pada Aplikasi Surat Tugas Perjalanan Dinas Pada Puskesmas Bati-Bati Berbasis Web yang sudah dikembangkan.

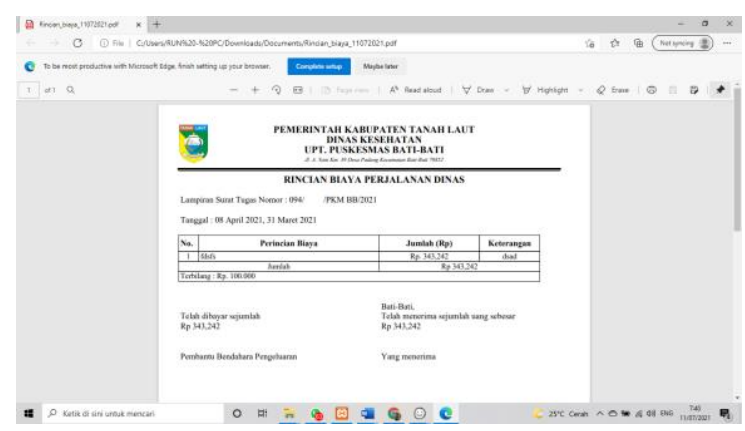

Gambar 9. Halaman Cetak Surat Tugas

Implementasi halaman cetak data Rincian Biaya berfungsi untuk mencetak seluruh proses dari data Rincian Biaya yang diajukan oleh super admin. Cetak surat ini akan bisa dilakukan apabila data Rincian Biaya telah terisi pada aplikasi. Jika data Rincian Biaya tidak ada maka user tidak akan bisa mencetak Rincian Biaya.

\section{Kesimpulan}

Bedasarkan hasil dari pembahasan laporan yang telah dituliskan oleh penulis, maka dapat disimpulkan bahwa:

a) Sistem ini sudah dapat melakukan kelola surat tugas mulai dari tambah, edit, hapus dan tampil. Selain itu juga dapat mencetak laporan.

b) Telah dirancang Entity Relationship Diagram (ERD) dengan tiga tabel entitas, Telah dirancang Data Flow Diagram (DFD) untuk membuat konsep penggambaran data apa saja yang ada pada sistem informasi, telah dirancang flowchart untuk menggambarkan sebuah proses alur dari aplikasi dan membuat rancangan antarmuka aplikasi.

\section{Referensi}

[1] Sudianto Aris, "Penerapan Website Sebagai Sarana Promosi Wisata Budaya pada Kabupaten Lombok Timur," Infotek J. Inform. dan Teknol., vol. 1Sudianto, no. 1, pp. 11-17, 2018.

[2] A. Sudianto and M. Wasil, "Penerapan Sistem Informasi Geografis dalam Pemetaan Sebaran Kasus Gizi Buruk Lombok Timur merupakan salah satu Kabupaten yang berada di Provinsi Nusa Tenggara Barat yang terletak di sebelah Timur Pulau Lombok, Kabupaten Lombok Timur Gizi Buruk Malnutrisi," vol. 4, no. 2, pp. 142-150, 2021.

[3] S. M. Sudianto Aris, "Penerapan Sistem Informasi Geografis (GIS) dalam Pemetaan Kerajinan Kain Tenun dan Gerabah untuk Meningkatkan Potensi Kerajinan di Kabupaten Lombok Timur," Infotek J. Inform. dan Teknol. J. Inform. dan Teknol., vol. 1, no. 2, pp. 64-71, 2018.

[4] A. Sudianto and M. Sadali, "Penerapan Aplikasi Berbasis Android Untuk Ternak Ayam Petelur Sebagai Wadah Untuk Menghubungkan Pemilik Modal Dengan Calon Peternak," Infotek J. Inform. dan Teknol., vol. 4, no. 1, pp. 87-95, 2021, doi: 10.29408/jit.v4i1.2999.

[5]. Abdulloh, R. (2016) 'Easy \& Simple Web Programming', Jakarta: PT Elex Media Komputindo, p. 227.

[6]. Abdulloh, R. (2018) '7 in 1 Pemrograman Web Untuk Pemula', PT Elex Media Komputindo, pp. 1-15. 
[7]. Christian, A., Hesinto, S. and Agustina, A. (2018) 'Rancang Bangun Website Sekolah Dengan Menggunakan Framework Bootstrap ( Studi Kasus SMP Negeri 6 Prabumulih )', Jurnal Sisfokom (Sistem Informasi dan Komputer), 7(1), p. 22. doi: 10.32736/sisfokom.v7i1.278.

[8]. Constantianus, F. and Suteja, B. (2005) 'Analisa dan Desain Sistem Bimbingan Tugas Akhir Berbasis Web dengan Studi Kasus Fakultas Teknologi Informasi', Jurnal Informatika, 1(2), pp. 93-106.

[9]. Effendy, F. and Nuqoba, B. (2016) 'Penerapan Framework Bootsrap Dalam Pembangunan Sistem Informasi Pengangkatan Dan Penjadwalan Pegawai (Studi Kasus:Rumah Sakit Bersalin Buah Delima Sidoarjo)', Informatika Mulawarman : Jurnal IImiah Ilmu Komputer, 11(1), p. 9. doi: 10.30872/jim.v11i1.197.

[10]. Firman, A. et al. (2016) 'Sistem Informasi Perpustakaan Online Berbasis Web', EJournal Teknik Elektro Dan Komputer, 5(2), pp. 29-36. doi: 10.35793/jtek.5.2.2016.11657.

[11]. Iswandy, E., Komputer, D. S. T. M. I. and Padang, S. J. (2015) 'Sistem Penunjang Keputusan Untuk Menentukan Dan Santunan Sosial Anak Nagari Dan Penyaluran Bagi Mahasiswa Dan Pelajar Kurang Mampu', jurnal TEKNOIF, 3(2). doi: 2338-2724.

[12]. Kusuma, W. F. (2015) 'Pengembangan Halaman Web Menggunakan XML dalam Perkembangan WEB 2.0', Jurnal Teknik Informatika, 6(2), p. 8.

[13]. Masrur, M. (2016) Pemrograman Web Dinamis Menggunakan Java Server Pages dengan Databases Relasional MYSQL. Yogyakarta: CV Andi Offset.

[14]. Mustaqbal, M. S., Firdaus, R. F. and Rahmadi, H. (2015) 'PENGUJIAN APLIKASI MENGGUNAKAN BLACK BOX TESTING BOUNDARY VALUE ANALYSIS
(Studi Kasus : Aplikasi Prediksi Kelulusan SNMPTN)', I(3), pp. 31-36.

[15]. Nugraha, F. et al. (2014) 'Analisa dan perancangan sistem informasi perpustakaan', 5(1), pp. 27-32.

[16]. Nurmawan, E. D. (2019) 'Sistem Informasi Kepegawaian Berbasis Website Pada PT Sumatera Panca Rajo Palembang', 5(2).

[17]. Pranata, D., Hamdani, H. and Khairina, D. M. (2015) 'Rancang Bangun Website Jurnal Ilmiah Bidang Komputer (Studi Kasus: Program Studi IImu Komputer Universitas Mulawarman)', Informatika Mulawarman : Jurnal Ilmiah Ilmu Komputer, 10(2), p. 25. doi: 10.30872/jim.v10i2.187.

[18]. Putri, S. I. and Sapoetra, Y. A. (2016) 'Perancangan Sistem Perpustakaan Online Menggunakan Metode Model View Controller ( MVC ) Studi Kasus STMIK Asia Malang', Jurnal IImiah Teknologi Informasi Asia, 10(2), pp. 17-23.

[19]. Reistiana, M. and Sukadi (2014) 'Sistem Informasi Penggajian Karyawan Pada Commenditaire Vennontschap (CV) RGL Bordir Dan Konveksi Pacitan', Speed Journal - Sentra Penelitian Engineering dan Edukasi - Volume 11 No 4 - 2014 ijns.org, 6(4), pp. 31-37.

[20]. Rosa, A.S. and Shalahuddin, M. (2016) Rekayasa Peragkat Lunak. Bandung: Informatika Bandung.

[21]. Rosa, A. S. and Shalahuddin, M. (2016) Rekayasa Perangkat Lunak Tersetruktur dan Berorientasi Objek. IV. Bandung: Informatika Bandung.

[22]. Sari, A. et al. (2019) 'DAYA MINERAL JAMBI', 1(4), pp. 249-264.

[23]. Soepomo, P. (2013) 'Membangun Aplikasi Autogenerate Script ke Flowchart untuk Mendukung Business Process Reengineering', Membangun Aplikasi Autogenerate Script Ke Flowchart Untuk Mendukung Business Process Reengineering, 1(2), pp. 448-456. doi: 10.12928/jstie.v1i2.2555. 